\title{
The protective effect of Fumaria officinalis against the testicular toxicity of fluoxetine in rat
}

\begin{tabular}{ccc}
\hline Abdalmuhaimn Y. Sharef & \\
\hline & Falah M. Aziz & Aveen N. Adham $^{3}$ \\
\hline & Abstract &
\end{tabular}

Background and objective: Extracts of Fumaria species have been traditionally used for the treatment of some skin diseases, rheumatism, stomach ache, fever, and male infertility mainly because of the presence of isoquinoline alkaloids. On the other side, fluoxetine is used as an antidepressant induce sexual dysfunction and a decrease in sperm concentration, motility, and morphology. The present investigation dealt with the study of the protective role played by the Fumaria officinalis extract against the selective serotonin reuptake inhibitor (SSRI) induced testicular toxicity in the rat. Therefore, the purpose of this work was to determine the benefits of Fumaria officinalis extract in animals treated with fluoxetine.

Methods: Thirty six male rats were divided into three following groups, control group, fluoxetine $(20 \mathrm{mg} / \mathrm{kg} / \mathrm{day})$ treated-group, and the same dose of Fluoxetine plus Fumaria officinalis extract $(150 \mathrm{mg} / \mathrm{kg} / \mathrm{day})$ as a third group. Drugs and extract were administered orally for 30 days. Sections of testes were stained by Haematoxylin and Eosin.

Results: Fluoxetine has caused several structural changes in the rat testis such as vacuolation within germinal epithelium of seminiferous tubules, decrease the diameter of these tubules and decrease number of sertoli and germinal cells. Treating the fluoxetine exposed rats with Fumaria officinalis extract has shown to ameliorate the above histological changes.

Conclusion: Fumaria officinalis extract can protect testis from histological alterations caused by the toxicity of the fluoxetine.

Keywords: Fumaria officinalis; Fluoxetine; Seminiferous tubules; Erbil city.

\section{Introduction}

Fluoxetine $\quad\{F L X\} \quad(N-M e t h y l-y-[4-$ (trifluoromethyl) phenoxy] benzene propanamine) is a Selective serotonin reuptake inhibitors (SSRI )and was approved by the US FDA in 1987. It is widely used to treat several disorders, such as major depression, anxiety, and premenstrual dysphoric disorder. ${ }^{1,2}$ Pharmacological evidence demonstrated that fluoxetine is a fluorine - including SSRI drug acting as an antidepressant agent with high absorption after oral administration. ${ }^{3}$ Fluoxetine inhibits the 5-hydroxytryptamine (5-HT) (Serotonin) reuptake. Increased synaptic availability of serotonin stimulates a large number of postsynaptic (5-HT) receptor subtypes which lead to complex secondary responses including gastrointestinal disturbances and sexual side effects which include loss of libido, delayed ejaculation, anorgasmia and impaired orgasm, decreased testicular development and decreased sertoli cell population, which may lead to infertility in adults. ${ }^{4}$ Elevation of the cerebral levels of 5-HT affects the secretion of follicle stimulating hormone $(\mathrm{FSH})$ and luteinizing hormone (LH), for inhibiting the liberation of gonadotrophins

${ }^{1}$ Department of Clinical Analysis, College of Pharmacy, Hawler Medical University, Erbil, Iraq

${ }^{2}$ Department of Biology, College of Science, Salahaddin University, Erbil, Iraq.

${ }^{3}$ Department of Pharmacognosy, College of Pharmacy, Hawler Medical University, Erbil, Iraq.

* Correspondence: abdulmuhaimn.sharef@hmu.edu.krd 
https://doi.org/10.15218/zjms.2020.015

releasing factor (GnRH) in the hypothalamus, with subsequent effects on the process of spermatogenesis and steroidogenesis in adult rats. ${ }^{5}$ Serotonin plays a role in spermatogenesis, and excess serotonin can lead to sperm dysfunction and its negative effects on semen parameters. ${ }^{6}$ Long-term ingestion of fluoxetine caused a decrease in spermatogenesis, testosterone, follicle stimulating hormone levels, and weights of reproductive organs in rats. ${ }^{7}$ Antidepressant medications can influence levels of sex steroids by altering the metabolism and protein binding of hormones. Additionally, they may influence fertility through peripheral effects as a result of their action on cholinergic and a-adrenergic receptors as well as through their effects on the production of viable spermatozoa. ${ }^{8}$ Fumitory species comprise the genus Fumaria, which belongs to the family Fumariaceae. There are around 60 species widely distributed all over the world and especially in the Mediterranean region, seven of which are Fumaria parviflora, Fumaria officinalis, Fumaria densiflora, and Fumaria capreolate. ${ }^{9}$ Fumitory is an annual plant of somewhat variable characteristics, often resembling a bush but also growing as a low trailing shrub. The plant is widespread and can be found in gardens, slopes, and wastelands. ${ }^{10}$ Previous phytochemical analysis of Fumaria officinalis has shown the presence of alkaloids such as protopine, cryptopine, stylopine, N-methylsinactine, fumaritine, fumariline, sanguinarine and polyphenols such as rutin and apigenin. ${ }^{11,12}$ Fumaria has been traditionally used for the treatment of rashes, fever, diarrhea, syphilis, and leprosy, ${ }^{13}$ also has aphrodisiac activity ${ }^{14}$ as well diuretic, depurative, anti-inflammatory, antiarrhythmic, antioxidant and antimicrobial activities. $^{15}$ The therapeutic effect of different Fumaria species for male infertility has been mentioned, ${ }^{16}$ but none was Fumaria officinalis included. The aim of the present study was to evaluate the protective effect of aerial parts Fumaria officinalis extract grown in Erbil, Kurdistan region against fluoxetine testotoxicity.

\section{Methods}

This study was carried out during the period of December 2017 to February 2018. The present work has been achieved on 36 male Wistar rats (6-month) with an average weight of $180-200 \mathrm{~g}$. All the groups of rats have been housed separately in different cages. The rats were divided into three groups (12 rats in each). The 1st group (A) rats received $1 \mathrm{ml}$ of normal saline for one month and considered as a control for groups $B$ and C. The 2nd group (B) was injected orally with only $1 \mathrm{ml}$ of $20 \mathrm{mg} / \mathrm{kg} /$ day of fluoxetine. The 3rd group (C) was injected with both $20 \mathrm{mg} / \mathrm{kg} /$ day of fluoxetine and $1 \mathrm{ml} 150$ $\mathrm{mg} / \mathrm{kg} /$ day of Fumaria officinalis orally by gavage. Experimental animals in each group treated daily for 30 days. They were maintained at temperature $\left(22 \pm 3^{\circ} \mathrm{C}\right)$ under a $12 \mathrm{~h}-12 \mathrm{~h}$ light-dark cycle with $50 \%$ to $60 \%$ humidity for at least one week before starting the experiment. Fluoxetine was dissolved in distilled water and was given orally to animals by gavages at dose $20 \mathrm{mg} / \mathrm{kg}$ body weight, equivalent to the therapeutic dose for humans, which is $20-60 \mathrm{mg} /$ day recommended range. $^{17}$ All experimental procedures in this study were approved by the Medical Research Ethics Committee of Pharmacy College in Hawler Medical University.

\section{Plant materials}

Aerial parts (leaves and stems) were collected from their natural habitats in Kurdistan region, Iraq. The Aerial parts were cleaned, cut into small pieces, air-driedd under shade for 5-7days, and stored in bottles until use. The identity of the plant was confirmed by the Department of Pharmacognosy, College of Pharmacy, Hawler Medical University, Iraq (Voucher No.A3). 


\section{Preparation of plant extract}

The dried aerial parts $(400 \mathrm{~g})$ were powdered in an electric grinder and extracted with ethanol $70 \%$ using ordinary reflex for $2 \mathrm{hr}$, then extract was filtered, and the filtrates were evaporated to dryness at low temperature under reduced pressure and the extract left behind (yield was 7 $\mathrm{g} / \mathrm{kg}$ ) was stored at $4^{0} \mathrm{c}$. It was dissolved in distilled water whenever needed for experiments.

\section{Histological examination of the testes}

After 30 days of exposure, both testes of all rats were dissected out after sacrificing the rats of all groups under ether anesthesia. The tissues were fixed in bouin fluid (picric acid $75 \mathrm{ml}+$ Formalin 25ml + Glacial acetic acid $5 \mathrm{ml}$ ), processed, and blocks were made in paraffin wax. $4-5 \mu \mathrm{m}$ thick sections were cut by a rotary microtome and stained with Haematoxylin and Eosin (H\&E). The sections were examined in the light microscope.

\section{Morphometric analysis}

Samples were analyzed using a motic plus2 microscope with an attached camera. All images were acquired digitally using Magna Fire Software (Optronics, Goleta, Calif). The testis net weight in rats was determined by the reduction of $6.5 \%$ from its gross weight. The reduction is related to the percentile of albuginea and mediastinum weight in rat testis (Testis Net Weight $=$ Testis gross weight $-6.5 \%$ ) . The germ cell nuclei and sertoli cell nucleolus at stage VII were counted in 10 round seminiferous tubules cross sections, chosen at random for each animal. ${ }^{18}$ The number of sertoli nucleus and vacuoles per each section were enumerated. Tubular diameter, epithelium height, were obtained by means of two diametrically opposite measurements. The stained sections were studied under a light microscope to evaluate spermatogenesis. Johnsen's criteria were used to categorize spermatogenesis. This system describes the preservation of spermatogenesis, on a scale from 1 to 10 , according to the absence or presence of the main cell types arranged in order of maturity. ${ }^{19}$ A score of 1 to 10 was given to each tubule according to the maturity of the germ cells: a score of 1 indicated no seminiferous epithelial cells and tubular sclerosis. A score of 2 indicated no germ cells, only Sertoli cells. A score of 3 indicated spermatogonia only. A score of 4 indicated no spermatids, few spermatocytes, and an arrest of spermatogenesis at the primary spermatocyte stage. A score of 5 indicated no spermatids and many spermatocytes. A score of 6 indicated no late spermatids, few early spermatids, the arrest of spermatogenesis at the spermatid stage, and disturbance of spermatid differentiation. A score of 7 indicated no late spermatids and many early spermatids. A score of 8 indicated a few late spermatids. A score of 9 indicated many late spermatids and disorganized tubular epithelium. A score of 10 indicated full spermatogenesis.

\section{Statistical analysis:}

The statistical analyses were carried out with the statistical package for the social sciences (version 24).Descriptive statistics were used to calculate the means and the standard deviations (SDs). One way ANOVA and Bonferroni were used to compare all groups. A $P$ value of less than or equal to 0.05 was considered as statistically significant.

\section{Results}

At the end of the experiment, it was observed that groups (B) and (C) rats, which were administrated fluoxetine for 30 days, showed a reduction in testis weight in comparison with the group (A) as a control group $(P=0.003)$. While no significant difference in testis weight was reported in group (C) compared to group (B) as shown in Table 1. The routine histological section showed a normal appearance of the testis in the control group (A) in which seminiferous tubules are lined with stratified epithelium and consists of spermatogenic cells and sertoli cells were seen to be abundant 
The protective effect of Fumaria officinalis .......

Zanco J. Med. Sci., Vol. 24, No. (1), April, 2020 https://doi.org/10.15218/zjms.2020.015

and healthy. The seminiferous tubule had a germinal epithelium without vacuoles a small lumen filled with sperm tails, and (Figure 1 and 2).

Table 1: Statistical analysis within groups A, B, and C.

\begin{tabular}{lcc}
\hline P( ANOVA) & & $P$ (Bonferroni) \\
\hline Testis net weight 0.003 & AxB & 0.003 \\
& AxC & 0.052 \\
Seminiferous tubule diameter $<0.001$ & BxC & 0.871 \\
& AxB & $<0.001$ \\
Epithelium height $<0.001$ & AxC & 0.151 \\
& BxC & 0.006 \\
Sertoli cell number $<0.001$ & AxB & $<0.001$ \\
& AxC & 0.119 \\
Johnsen's Score $<0.001$ & BxC & 0.003 \\
& AxB & $<0.001$ \\
& AxC & 0.280 \\
& BxC & 0.012 \\
& & $<0.001$ \\
& AxB & 1.000 \\
& AxC & $<0.001$ \\
& BxC & $<0.001$ \\
& & 0.012 \\
& AxB & 0.008 \\
\hline
\end{tabular}




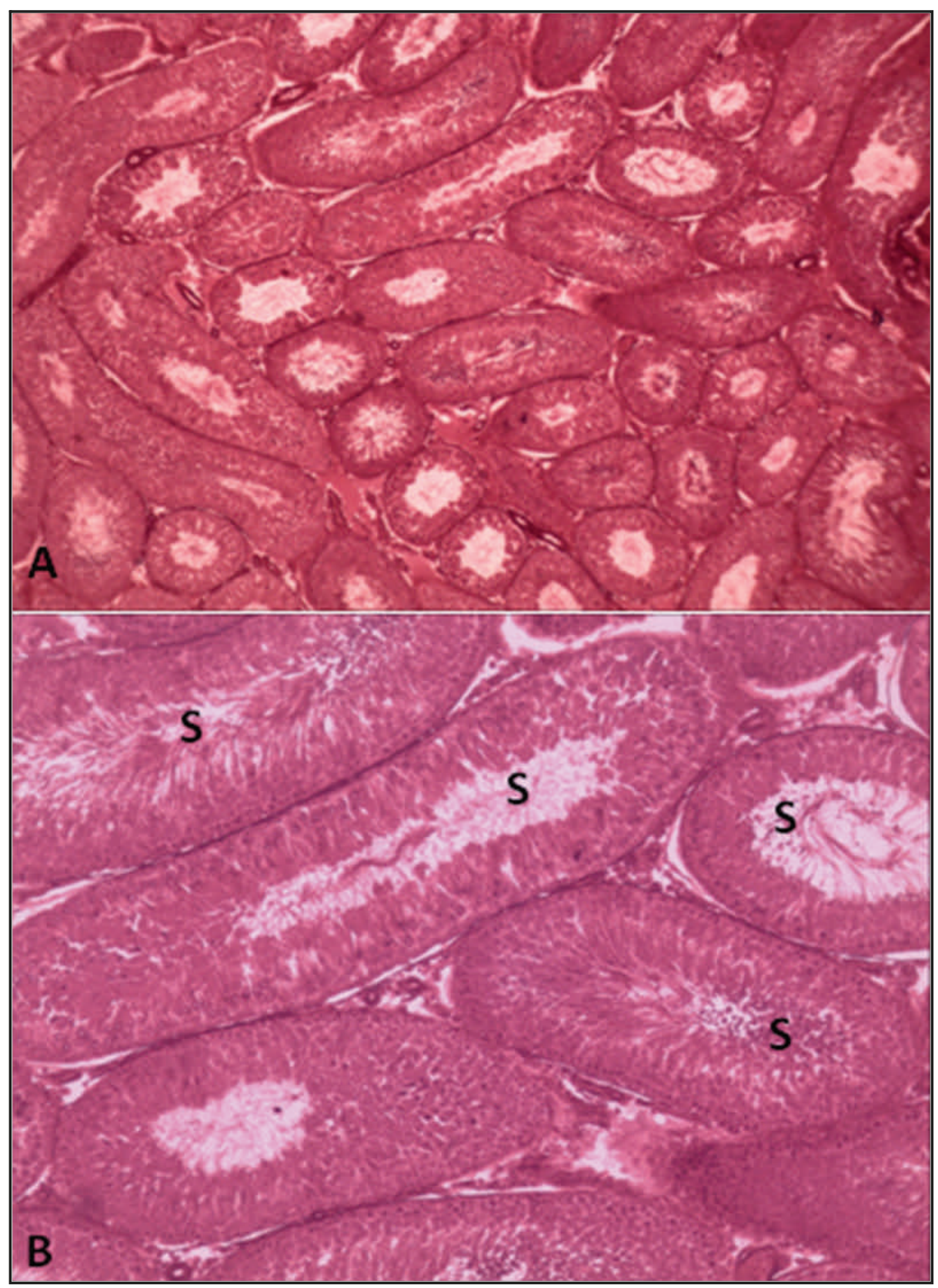

Figure 1: Sections through the testis of rat in the control group showing the normal histological structure of seminiferous tubules (S) with lumen filled with spermatids. $\mathrm{H} \& E, A) 40 x, B) 100 x$ 


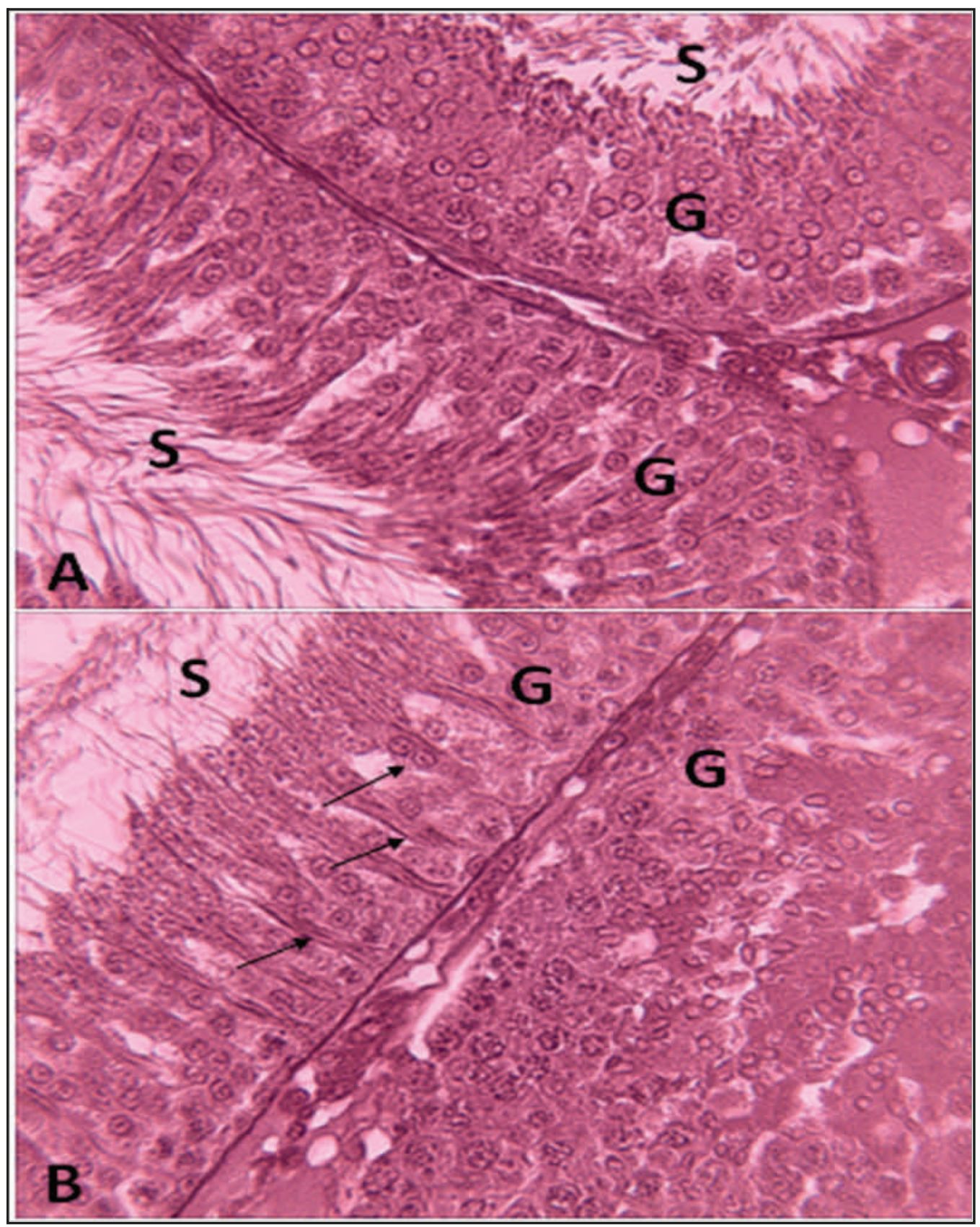

Figure 2: Sections through the testis of rat in the control group showing the seminiferous tubules (S) and the normal appearance of the germinal layer (G), (arrows): Sertoli cells. Both Figures are 400X H\&E 
In comparison with the control group (A), the testes of the fluoxetine treated group (B) showed several histological alterations, as shown in Table 2, a significant decrease in the diameter of seminiferous tubules and thickness of its germinal epithelium $(P<0.001)$. Signs of distortion of the seminiferous tubules, approximately empty lumen and depleted germinal layer were observed. Sertoli cells per transversal section were found to be decreased statistically in number $(P<0.001)$. Many large vacuoles within germinal epithelium have also appeared. Furthermore, damaging of boundary and the interstitial tissue which connect the seminiferous tubule was also seen (Figures 3-5).

Table 2: Biometric aspects of the testis in the three groups (mean $\pm S D$ ).

$\begin{array}{llll}\text { Parameters } & \text { Group (A) N=12 Group (B) N=12 Group ( C ) N=12 }\end{array}$

Testis net weight $(g)$

Seminiferous tubule diameter $(\mu \mathrm{m})$

Epithelium height $(\mu \mathrm{m})$

Sertoli cell number / cross Section

\section{Vacuole number/cross} Section

Johnsen's Score
$1.14 \pm 0.12$

$0.89 \pm 0.19$

$0.96 \pm 0.18$

$302.08 \pm 7.21$

$275.91 \pm 14.83$

$292.16 \pm 12.53$

$95.25 \pm 4.90$

$79.08 \pm 8.17$

$89.25 \pm 7.11$

$7.75 \pm 0.96$

$5.41 \pm 1.08$

$6.91 \pm 1.44$

$0.58 \pm 0.66$

$2.25 \pm 0.62$

$0.83 \pm 1.02$

$9.41 \pm 0.66$

$6.33 \pm 1.55$ 


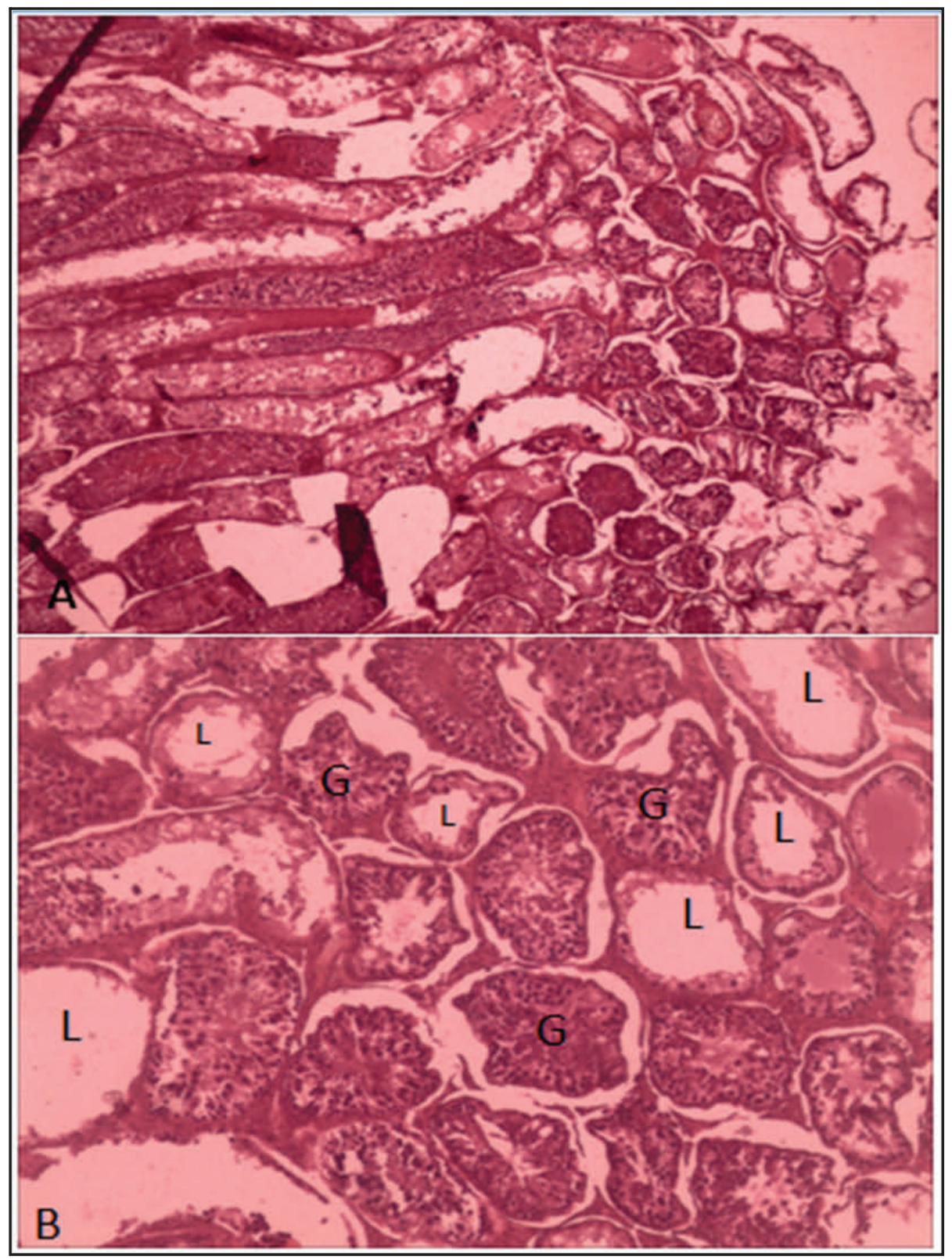

Figure 3: Sections through the testis of rat in fluoxetine treated group showing the Shrunken seminiferous tubules, some of which appear with the empty lumen (L) and the depleted germinal layer (G). Both Figures are 400X H\&E 


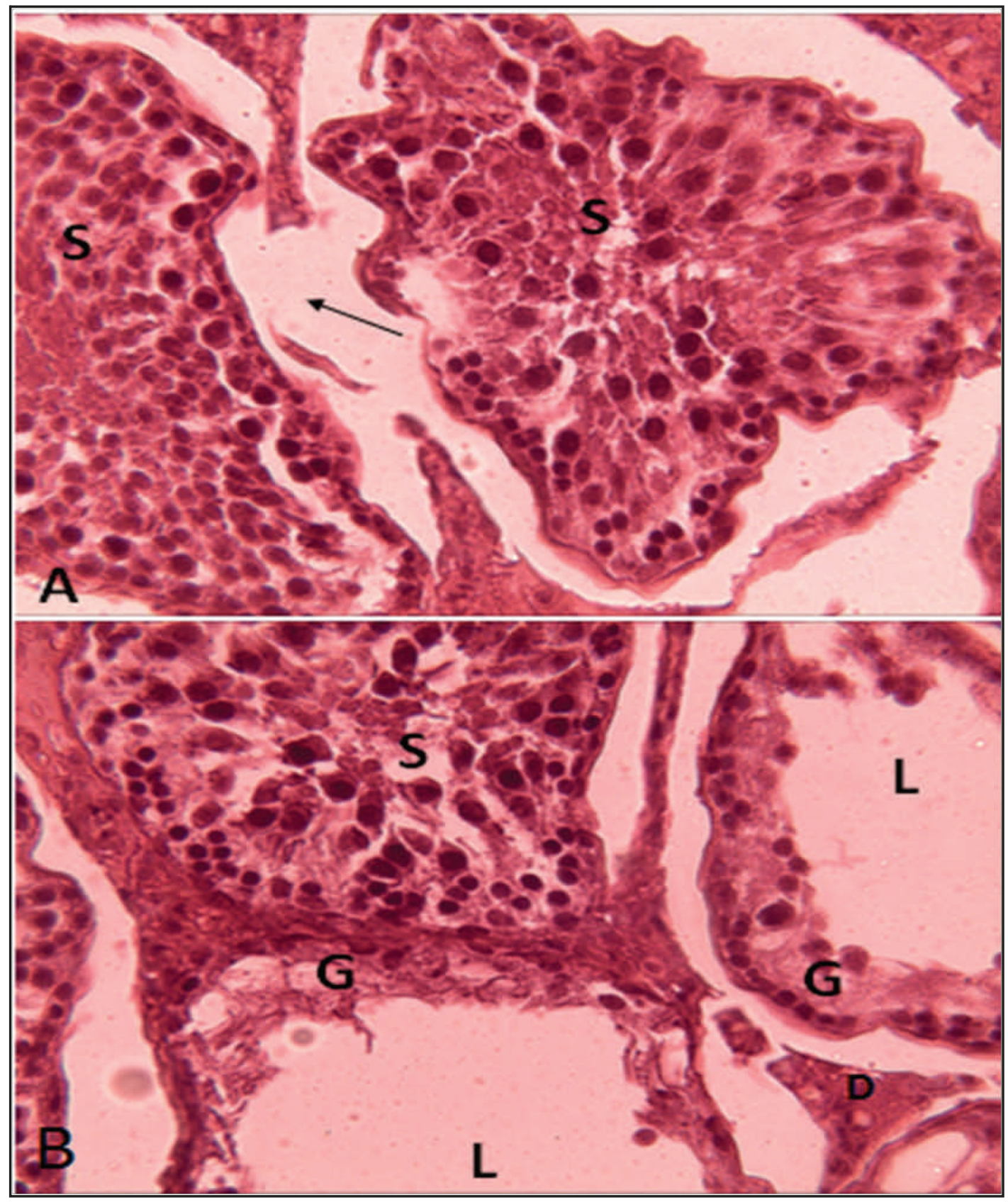

Figure 4: Higher magnification of Figure 3 showing: A) Shrunken seminiferous tubules $(\mathrm{S})$, Notice the spermatogonia arrested in prophase and the damaging of interstitial tissues (arrow), B) No progress in mitosis and empty seminiferous lumen (L) with depleted germinal epithelium (G). Both H\&E, 400X 


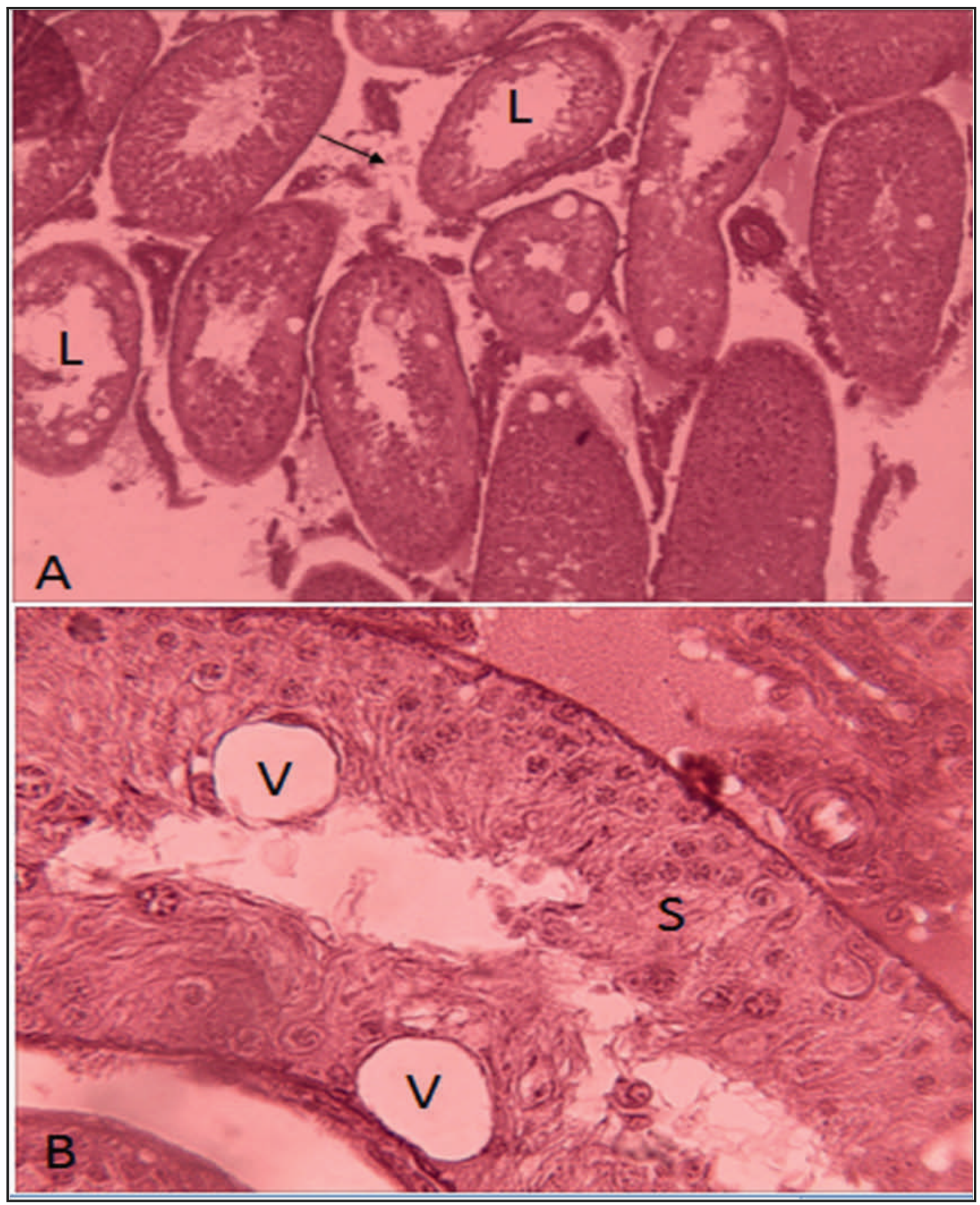

Figure 5: Sections through the Fluoxetine treated rats showing $(A)$ damaging of the interstitial tissues (arrow), vacuolation of the germinal epithelium $(S)$ with empty lumen $(L)$, 100X B) Vacuoles (V), 400X 
Several tubules showed shrunk with decrease in the germinal cell population (Spermatogonia, primary and secondary spermatocytes, spermatids, and mature sperm numbers). So, Johnsen's Score showed a significant decrease in group (B) in comparison with control rats $(P<0.001)$. On the other hand, Fluoxetine plus Fumaria -treated rat testis showed approximately normal histological appearance in comparison to fluoxetine treated group. The lumen of the seminiferous tubules were seen full of spermatid with variable mitotic and meiotic stage in the germinal epithelium (Figures 6 and 7).

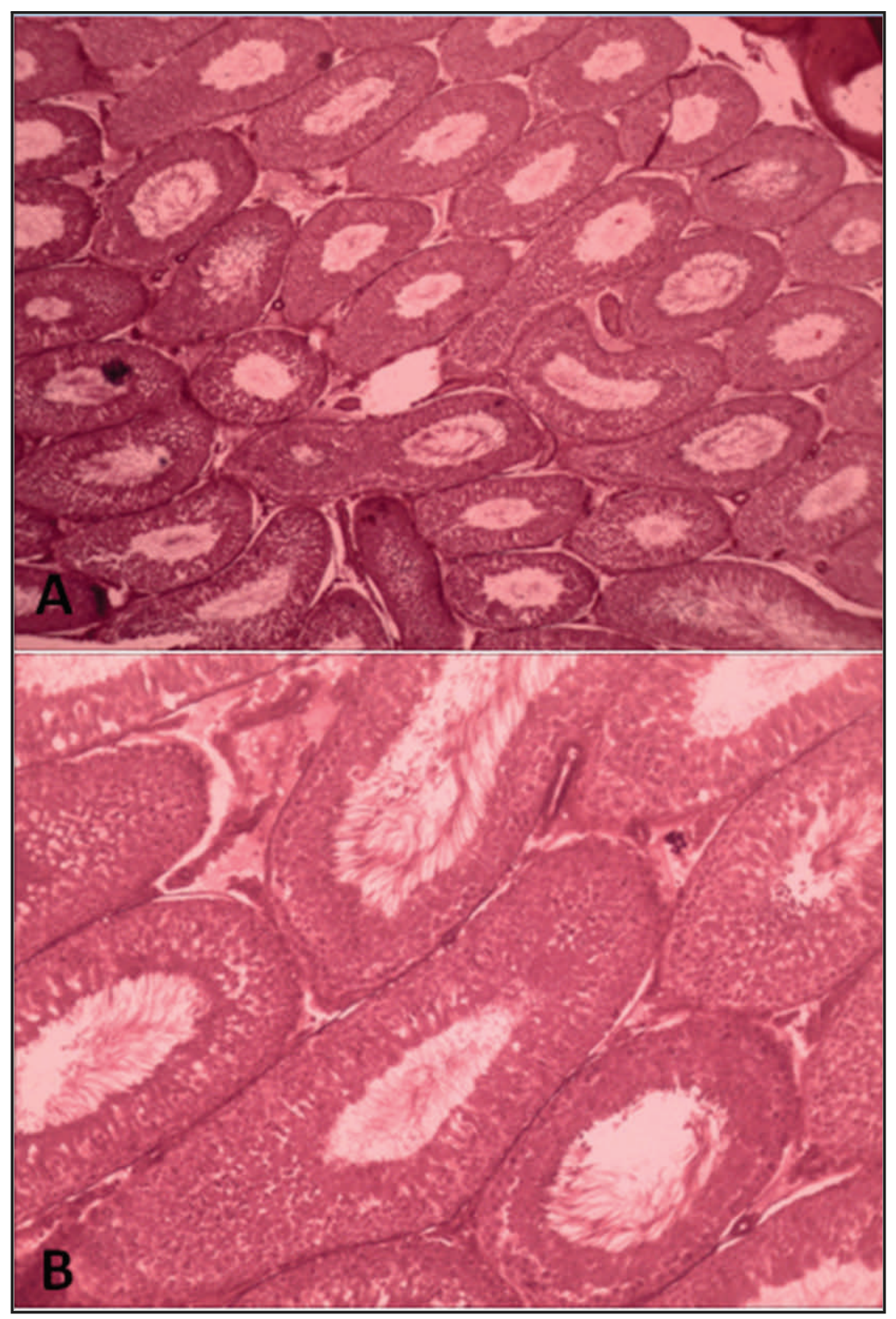

Figure 6: Sections through Fluoxetine plus Fumaria treated rat testis showing the approximately normal histological appearance of the seminiferous tubules with lumen filled with spermatids, A) 40X, B) 100X, both H\&E 
https://doi.org/10.15218/zjms.2020.015

Results in Table 2 show that a statistically significant increase occurred on seminiferous tubule diameter, the thickness of germinal epithelium, and number of sertoli nucleus per cross section of seminiferous tubule in the group (C). While other parameters like the number of vacuoles were decreased significantly (Figure 5). In regard to the cell population of seminiferous tubule, there was a significant increase in Johnsen's Score $(P=0.008)$ as compared to group B.

\section{Discussion}

This study included evaluation protective effect of Fumaria officinalis against the testicular toxicity of fluoxetine were performed for the first time in Erbil city. The present study demonstrated that the administration of fluoxetine has toxicant effect on the reproductive system. A reduction of testicular weight among animals treated with $20 \mathrm{mg} / \mathrm{kg}$ of fluoxitine was observed when compared to control group. Many researchers have shown that any change or alteration in the androgen level results in general decrease in testicular weight. ${ }^{20}$ In addition, testicular weight is a morphometric parameter directly and positively related to seminiferous tubules total length, sertoli cell population and spermatic production. ${ }^{18}$ This results corroborates other findings who reported that in a one -year oral toxicity of $20 \mathrm{mg} / \mathrm{kg}$ fluoxetine in beagle dogs was associated with reduction in absolute and relative testis weight by $26 \%$ and $33 \%$ respectively. ${ }^{21}$ Our experimental design aimed to identify the positive effect of Fumaria officinals extract on testicular development in animals treated with fluoxetine. The results of this study showed an increase in testicular weight in animals treated with extract, however, it was not significant $(P=0.871)$, our findings were similar to findings of previous study ${ }^{22}$ who used Fumaria parviflore. A study confirmed by AlkAggrwal et al. ${ }^{23}$ that the distortion of

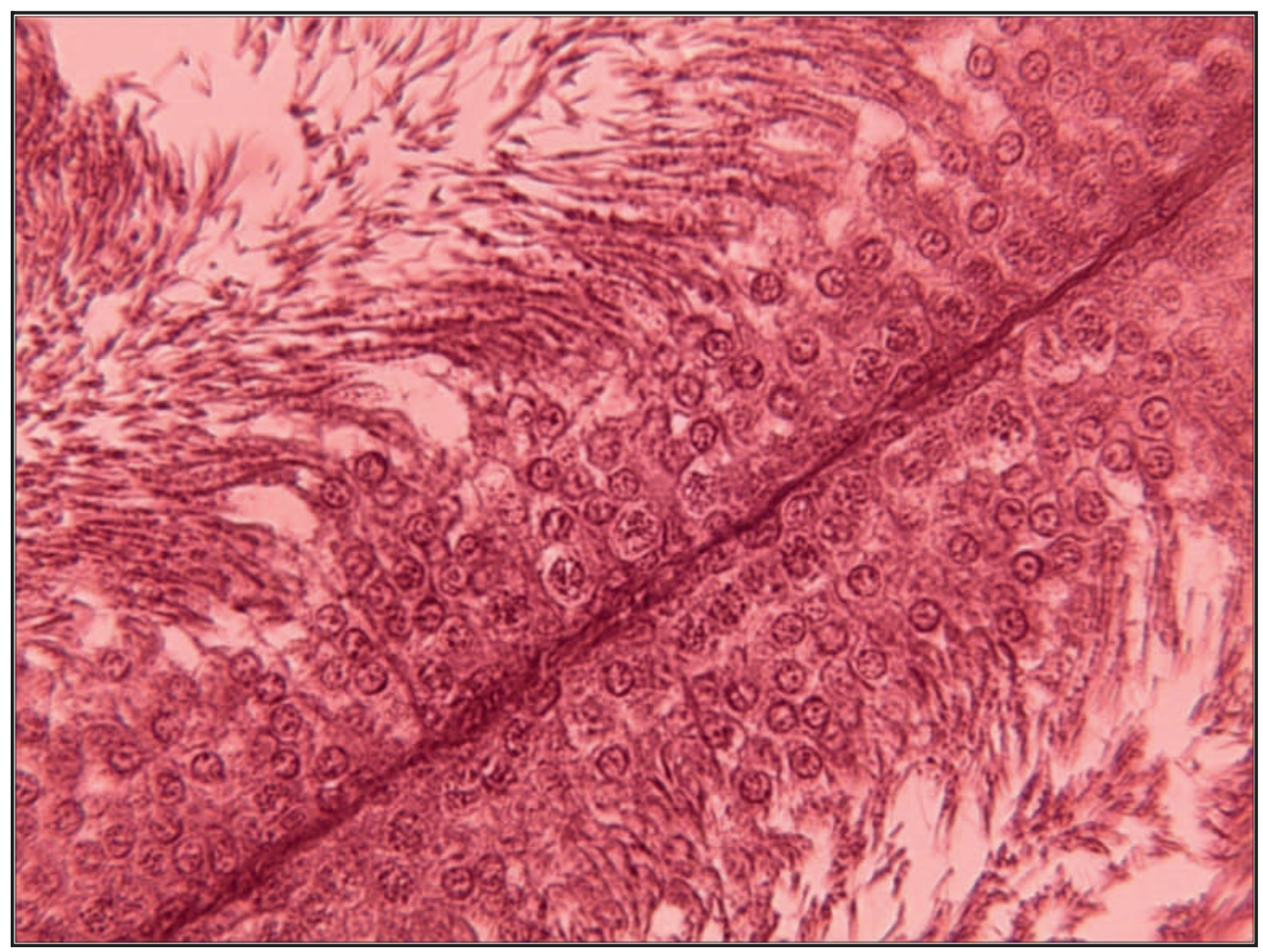

Figure 7: Sections through the testis of Fluoxetine plus Fumaria treated rats showing the normal histological appearance of the seminiferous tubules with lumen filled with spermatids, both are 400X, H\&E. 
seminiferous tubules, decreased thickness of the germinal epithelium, decreased diameters of seminiferous tubules were observed in rat treated with $20 \mathrm{mg} / \mathrm{kg}$ of fluoxetine for four weeks. These findings were similar to our results in present study, as well as we found disruption of the seminiferous tubular epithelium with focal damages ranging in severity from increased degeneration of spermatogenic cell profiles to complete loss of the germinal epithelium. ${ }^{23}$ According to Ortega Pachco et al., ${ }^{24}$ the hormones, neoplasias, irradiation, trauma, and others interrupt the spermatogenic process, initially characterized by germinative cells desquamation in the tubular lumen and by a decrease in seminiferous epithelium height, necrosis and apoptosis of germinative epithelium cells and hyalinization of seminiferous tubules. The present work demonstrated many histological alterations in rats testicular tissue due to fluxetine exposure these findings are similar to other many previous studies. Silva et al. ${ }^{5}$ reported a reduction between 30 and $32 \%$ in the number of sertoli cells per testis in animals treated with $20 \mathrm{mg} / \mathrm{kg}$ fluxetine. AlkaAgg ${ }^{23}$ also observed that as the duration and dose of fluoxetine increased the entire cell lineage (Sertoli cells, Spermatogonia A, pale and dark type, Spermatogonia B, Primary spermatocytes) of the germinal epithelium decreased in number, however, this work used Johnsen's score to categorize spermatogenesis. Fluoxetine caused marked cessation of spermatogenesis via elevating the level of serotonin which stimulates suppression of hypothalamus-pituitary-testis axis mediated by activated hypothalamus-pituitaryadrenocortical axis resulting in decline of plasma luteinizing hormone (LH), Follicle stimulating hormone (FSH) and testosterone normal range. Testosterone and Follicle stimulating hormone act directly upon germinal epithelium. ${ }^{25}$ Moreover, animals treated with $20 \mathrm{mg} / \mathrm{kg}$ of fluoxetine showed lack of spermatogenesis inside the tubules, shrinkage tubules with wide intertubular space, and degeneration of seminiferous tubules. ${ }^{26}$ The results in the present study observed that Fumaria officinalis increases seminiferous tubule diameter, epithelium height, number of sertoli cells, in rats treated with fluoxetine and extract compared to rats treated with only fluoxetine. Thus Fumaria officinalis has positive effects on testicular structure in this work might be due to the existence of antioxidant component. Studies have indicated that Fumaria officinalis contain high amount of isoquinoline alkaloids such as protopine, fumaricine, sanguinarine and so on, and polyphenols such as rutin and apigenin, these materials have antioxidative activity. ${ }^{11,12}$ Antioxidant composition can protect cell membrane from damage, ${ }^{22}$ caused by fluoxetine, which might be lead to atrophy of seminiferous tubule and depletion of the germinal epithelium (Figure 4). The antioxidant capacity of Fumariaspp due to the high content of flavonoids has been proved $^{27}$ and the ethanolic extract of Fumaria officinalis was found to be able to inhibit the lipid peroxidation ${ }^{28}$ and has been found to exert an antioxidant activity. ${ }^{29}$ This may explain the protective effect of the ethanolic extract of Fumaria officinalis against the oxidative stress production by fluoxetine in testis cells and tissue of rats as revealed by the present work. Souriel et al. ${ }^{30}$ reported that Fumaria parviflora protect number of spermatogonium, spermatocytes, spermatozoids and sertoli cells from damage. Therefore histological Examination of testicular tissue in Fumaria officinals treated rats showed marked improvement in histological changes, a little degenerated germ cells with seldom vacuoles of epithelium (Figure 5, 6). In addition, Johnsen's Score was significantly increased (Table 2). These results confirm the protective effect of Fumaria officinals. Other species of Fumaria effect on the testis tissue by increasing number of Leydig cell and there 
upon increase in testosterone hormone and more blood flow to the testis through angiogenesis increasing led to raising the number of sertoli cells which control spermatogenesis, and improve cells within epithelium ${ }^{22}$ because the structural and functional probity of reproductive organs depends on the amble bioavailability of testosterone. ${ }^{16}$ Mukhtar et al. ${ }^{14}$ mentioned the aphrodisiac activities of Fumaria officinalis. This action might induce the process of spermatogenesis, leading to increasing of germinal cells number. All of the mechanisms mentioned above give the possibility of Fumaria officinalis to preserve the histological structure of seminiferous tubules and its germinal cells.

\section{Conclusion}

The study concluded that Fumaria officinalis minimize the side effects of flouxetine on testicular structure. Histological results of the present work confirmed the previous study that fluoxetine caused testicular dysfunctions in rats.

\section{Competing interests}

The authors declare no competing interests.

\section{References}

1. Sharma A. Anorexia nervosa and bulimia nervosa: An appraisal. Drugs Today (Barc) 2001; 37(4):229-36.

2. Vaswani M, Linda FK, Ramesh S. Role of selective serotonin reuptake inhibitors in psychiatric disorders: a comprehensive review. Prog Neuro psycho pharmacol Biol Psychiatry 2003; 27(1):85-102.

3. Mielniczuk L, DeKemp RA, Dennie C, Yoshinaga $K$, Burwash IG, Bénard $F$, et al. Images in cardiovascular medicine. Fluorine-18-labeled deoxyglucose positron emission tomography in the diagnosis and management of aortitis with pulmonary artery involvement. Circulation 2005; 111(22):375-6.

4. Ross JB. Drugs and the treatment of psychiatric disorders in depression and anxiety disorders. Goodman and Gillman's. The pharmacological basis of therapeutics. $10^{\text {th }}$ ed. New York: Mc Graw-Hill Companies; 2001. P. 447-83.

5. Silva JVA, Lins AMJ, Amorim AA, Pinto FC, Deiró TBJ, de Oliveira JRM, et al. Neonatal administration of fluoxetine decreased final sertoli cell number in Wistar rats. Int $\mathrm{J}$ Morphol
2008; 26(1):51-62.

6. Ortiz Á, Espino J, Bejarano I, Lozano GM, Monllor F, García JF, et al. The correlation between urinary 5-hydroxyindoleacetic acid and sperm quality in infertile men and rotating shift workers. Reprod Biol Endocrinol 2010; 8(1):138.

7. Bataineh HN, Daradka T. Effects of long-term use of fluoxetine on fertility parameters in adult male rats. Neuro Endocrinol Lett 2007; 28(3):321-5.

8. Hendrick V, Gitlin M, Altshuler L, Korenman S. Antidepressant medications, mood and male fertility. Psycho Neuro Endocrinol 2000; 25(1):37 $-51$.

9. Jaberian H, Piri K, Nazari J. Phytochemical composition and in vitro antimicrobial and antioxidant activities of some medicinal plants. Food Chem 2013; 136(1):237-44.

10. Mingli Z, Lidén M. Fumaria Linnaeus, Sp. Flora of China 2008; 7:428.

11. Patel A, Shenouda N, Tallis G. PDR for Herbal Medicines. $4^{\text {th }}$ ed. Thomson Healthcare, Montvale; 2007.

12. Suau R, Cabezudo B, Rico R, Najera F, López-Romero JM. Direct determination of alkaloid contents in Fumaria species by GC-MS. Phytochemical Analysis. An Int J Plant Chem Biochem Tech 2002; 13(6):363-7.

13. Maiza-Benabdesselam $\mathrm{F}$, Khentache $\mathrm{S}$, Bougoffa K, Chibane M, Adach S, Chapeleur Y, et al. Antioxidant activities of alkaloid extracts of two Algerian species of Fumaria: Fumaria capreolata and Fumaria bastardii. Rec Nat Prol 2007; 1(2-3):28.

14. Mukhtar GZ, Chrioma BA, Zainab R, Muhmmad Al, Ibrahim Y, Yunusa I. Cinnamomun cassia, Ficus carica and Fumaria officinalis possesses aphrodisiac activity in male Wister rats. Ann Exp Bio 2015; 3(3):14-7.

15. Sengul M, Yildiz H, Gungor N, Cetin B, Eser Z, Ercisli S. Total phenolic content, antioxidant and antimicrobial activities of some medicinal plants. Pak J Pharm Sci 2009; 22(1):102-6.

16. Dorostghoal M, Seyyednejad SM, Khajehpour L, Jabari A. Effects of Fumaria parviflora leaves extract on reproductive parameters in adult male rats. Iran J Reprod Med 2013; 11(11):891.

17. Walia V, Gilhotra N. GABAergic influence in the antidepressant effect of fluoxetine in unstressed and stressed mice. J Appl Pharm Sci 2017; 7(03):141-7.

18. Silva Junior VA, Monteiro Filho O, Ferreira Pinto C, de Torres SM, Mendes Tenorio B. Testis evaluation of adult Wistar rats after neonatal treatment with fluoxetine. Acta Sci Biol Sci 2013; 35(1):115-22.

19. Erdemir F, Atilgan D, Firat F, Markoc F, Parlaktas BS, Sogut E. The effect of sertraline, paroxetine, fluoxetine and escitalopram on testicular tissue and oxidative stress parameters in rats. Int Braz J Urol 2014; 40(1):100-8.

20. Geetha U. Post treatment analysis of fluoxetine 
hydrochloride on testis of wistar rats. Int J STEM Educ 2017; 5(1):2321-9009.

21. National Toxicology Program. NTP-CERHR monograph on the potential human reproductive and developmental effects of fluoxetine. NTP CERHR MON 2004; (13):i-III24.

22. Nasrabadi MH, Aboutalebi $\mathrm{H}$, Naseri M. Effect of Fumaria parviflora alcoholic extract on male rat's reproductive system. J Med Plants Res 2012; 6(10):2004-10.

23. Aggarwal A, Jethani S L, Rohatgi R K, Kalra J. Effects of Fluoxetine on Testis of Albino rats. A Histological Assessment. Int J Sci Eng Res 2012; $3(7): 1-5$.

24. Ortega-Pacheco A, Rodríguez-Buenfil JC, Segura-Correa JC, Bolio-Gonzalez ME, JiménezCoello M, Linde Forsberg C. Pathological conditions of the reproductive organs of male stray dogs in the tropics: prevalence, risk factors, morphological findings and testosterone concentrations. Reprod Domest Anim 2006; 41(5):429-37.

25. Aggarwal A, Jethani S L, Rohatgi R K, Kalra J. Effect of Fluoxetine on epididymis of albino rats: A Histological study. Int J Sci Eng Res 2013; 4(8):1457-62.

26. Unnikrishnan G, Shivabalan R, Lillian J. Sub-acute toxicity of fluoxetine hydrochloride on fertility of male wistar rats. J Herb Med Toxicol 2009; 3:23-30.

27. Ivanov I, Vrancheva RZ, Marchev AS, Petkova NT, Aneva IY, Denev PP, et al. Antioxidant evaluation of their antioxidant and antibacterial activities, Industrial Crops and activities and phenolic compounds in Bulgarian Fumaria species. Int J Curr Microbiol App Sci 2014; 3:296 -306 .

28. Wasu SJ, Muley BP. Antioxidant activity of Fumaria officinalis Linn. and its study on ethanol induced-immunosupression. Res $\mathrm{J}$ Pharm Technol 2009; 2(2):405-8.

29. Khamtache-Abderrahim $S$, Lequart-Pillon $M$, Gontier E, Gaillard I, Pilard S, Mathiron D, et al. Isoquinoline alkaloid fractions of Fumaria officinalis: Characterization and evaluation of their antioxidant and antibacterial activities. Ind Crops Prod 2016; 30(94):1001-8.

30. Souri M, Heydari NM, shiravi A, Habibi Z. Interaction between Fumaria parviflora aqueous extract and cholorambocil on spermatogenesis in rats. J Animal Biol 2009; 2(1):11-8. 